\title{
Article \\ Empirical Estimation of Intraday Yield Curves on the Italian Interbank Credit Market e-MID
}

\author{
Anastasios Demertzidis ${ }^{1, *}$ and Vahidin Jeleskovic ${ }^{2}$ \\ 1 Department of Economics, Applied Microeconomics and Quantitative Methods in Economics, University of \\ Kassel, Nora-Platiel-Str. 4, D-34109 Kassel, Germany \\ 2 Department of Economics, Unit Empirical Economic Research, University of Kassel, Henschelstr. 4, \\ D-34127 Kassel, Germany; Jeleskovic@uni-kassel.de \\ * Correspondence: Demertzidis@uni-kassel.de; Tel.: +49-561-804-7267
}

Citation: Demertzidis, Anastasios, and Vahidin Jeleskovic. 2021.

Empirical Estimation of Intraday Yield Curves on the Italian Interbank Credit Market e-MID. Journal of Risk and Financial Management 14: 212. https://doi.org/10.3390/jrfm14050212

Academic Editor: Goran Buturac

Received: 25 March 2021

Accepted: 29 April 2021

Published: 8 May 2021

Publisher's Note: MDPI stays neutral with regard to jurisdictional claims in published maps and institutional affiliations.

Copyright: (c) 2021 by the authors. Licensee MDPI, Basel, Switzerland. This article is an open access article distributed under the terms and conditions of the Creative Commons Attribution (CC BY) license (https:// creativecommons.org/licenses/by/ $4.0 /)$.

\begin{abstract}
This paper introduces a major novelty: the empirical estimation of spot intraday yield curves based on tick-by-tick data on the Italian electronic interbank credit market (e-MID). To analyze the consequences of the recent financial crisis, we split the data into four periods, which include events before, during, and after the recent financial crisis starting in 2007. Our first result is that, from a practical point of view, the intraday yield curve can be modeled by standard models for yield curves providing advantages for intraday trading on intraday interbank credit markets. Moreover, the estimates show that the systematic dynamics in the intraday yield curves during the turmoil were highly noticeable, resulting in a significantly better goodness-of-fit. Based on this fact, we infer that investors in the interbank credit market base their investment decisions on the effects of the intraday dynamics of intraday interest rates more intensively during a financial crisis. Therefore, the systematic impact on the e-MID appears to be stronger and econometric modeling of the intraday interest rate curve becomes even more attractive during a turmoil.
\end{abstract}

Keywords: interbank credit market; e-MID; Nelson-Siegel model; intraday yield curve estimation; financial crisis

\section{JEL Classification: C13; C58; E43; G01}

\section{Introduction}

The yield curve, which models the relationship between interest rates and various maturities, and thus quantifies the interest rate movements based on the maturity of bonds or credits, has been analyzed, especially from a macroeconomic point of view, in many studies (e.g., Ang and Piazzesi 2003; Diebold et al. 2005; Piazzesi 2005; Diebold et al. 2006; Rudebusch and Wu 2008; Afonso and Martins 2012). The majority of the papers study the behavior of government bond yield curves, meaning interest rates with high maturities, of one month to 30 years. Furthermore, several researchers analyzed the effects of the recent financial crisis on interest rates, in particular on the yield curve (e.g., Guidolin and Tam 2013). In this paper, the concept of the yield the curve on the interbank credit market and, more interestingly, on the intraday frequency is introduced for the first time by taking account the effects of a financial crisis in the empirical part. For these purposes, we rely on the model introduced by Nelson and Siegel (1987).

The model of Nelson and Siegel (1987) (hereafter NSM) presents a breakthrough in the parsimonious modeling of yield curves and is often used in both theory and practice due to its empirically proven goodness-of-fit and the implied conforming behavior of long-term yields (Niu and Zeng 2012; Aljinović et al. 2012). The NSM has been empirically verified by different researchers (see, e.g., Ganchev 2009; Kladívko 2010; Aljinović et al. 2012). In this line, the NSM is used by many researchers (see, e.g., Hladíková and Radová 2012; Cassino et al. 2014; Meier 1999), individual investors as well as large banks and central banks, 
including those of Belgium, Finland, and Italy (BIS 2005). For the economic interpretation of the yield curve see e.g., the expectation hypothesis see, e.g., Estrella and Hardouvelis (1991); Estrella and Mishkin (1999) and for the NSM, e.g., Gürkaynak et al. (2007). Furthermore, the model is used also by practitioners, for example, by fixed income portfolio managers, to strengthen their portfolios (Hodges and Parekh 2006).

Only a few studies focus on the estimation of the yield curve on different interbank credit markets. Due to the reliability of those markets and the short maturity of the interbank credits, there was no strong research focus on interbank credit markets until the outbreak of the financial crisis in 2007 (De Socio 2013; Hatzopoulos and Iori 2012). Hurn et al. (1995) estimate the yield curve for the LIBOR of one, three, six and twelve months. Ametrano and Bianchetti (2009) estimate the yield curve for the EURIBOR of one, three, six and twelve months. Reppa (2008) estimates the yield curve using, among other rates, BUBOR (Budapest Interbank Offer Rate) rates for maturities of two weeks and from one to twelve months.

The question arises as to why banks participate in the interbank credit markets. The primary function of those markets is to allocate liquidity among banks. This liquidity is originally provided by the central bank of each banking system (Wiemers and Neyer 2003). However, banks may generate a liquidity crunch, expect one, or may alternatively generate a liquidity surplus. In both cases, banks might be motivated to act on interbank credit markets (Vento and La Ganga 2009). This is also the case for the interbank credit markets on intraday time frequencies. Thus, the price of intraday money, that is the intraday interest rate, affects the liquidity management of those banks and moreover, is also informative in order to understand the payment system as well as the implications of different policies of central banks, by providing intraday credits (Baglioni and Monticini 2008) and in order to settle obligations in payment and settlement systems (Ball et al. 2011).

The interbank credit markets are also crucial to the functionality of all financial systems. The interbank credit market is the first channel of monetary policy transmission and plays an important role for the borrowing and lending of households and firms (Affinito 2012). Furthermore, a well-functioning interbank market channels liquidity effectively from institutions with a cash surplus to institutions with cash shortages. From a policy maker's point of view, a well-functioning interbank credit market is of high interest, since it helps to achieve the desired interest rates, which allows to trade liquidity effectively (Furfine 2002). In stable times the interbank interest rates are determined by the orientations of the monetary policy.

Most interbank credit markets are over-the-counter markets. There, market prices (interest rates) and transaction volumes are not publicly known. One exception is the Italian electronic interbank credit market-Mercato dei Depositi Interbancario-e-MID (Bonner and Eijffinger 2013). The e-MID market is a fully transparent market and the only electronic market for interbank deposits in the Eurozone and the US (Hatzopoulos et al. 2015).

Based on the above mentioned arguments, the goal of this paper is the estimation and empirical analysis of the spot intraday yield curves (hereafter SIYC-s) for the e-MID market. According to data from the European Central Bank (ECB) this market accounted for about $17 \%$ of the total turnover in the unsecured money market in the Eurozone before the financial crisis (ECB 2011). Furthermore, one advantage of this market is that the rates on the e-MID reflect actual transactions and do not suffer from potential distortions or manipulating scandals affecting other rates, such as the LIBOR or the EURIBOR (Angelini et al. 2011).

Due to the fact that the overnight segment is the most important segment of the interbank credit market (Green et al. 2016) and given our calculations that about $90 \%$ of credits, in terms of volume and absolute number of credits, on the e-MID are overnight credits, it is intuitive to take into account the intraday dynamics of the yield curve of overnight credits and to model them by applying the NSM.

There is a certain amount of published papers and studies of econometric modeling and estimating the yield curve on low frequency using NSM (and its extensions and 
modifications). However, to the best of our knowledge, there are no papers analyzing the SIYC-s on interbank credit markets.

On the other side, there is a certain amount of papers analyzing the intraday interest rate on the e-MID. Angelini (2000) was the first to analyze the intraday rate in the e-MID from July 1993 to December 1996 by constructing an intraday curve using hourly means of the intraday interest rates. During his analysis, he finds only some weak evidence for a downward intraday interest rate.

Baglioni and Monticini (2008) also postulate a concept of an intraday interbank rate curve for the e-MID market, starting with the question whether there is a market price for intraday money on the e-MID market. Gabbi et al. (2012) call this intraday term structure of interest rates also a yield curve. In this context, the authors claim, using hourly averages of the intraday interest rate, that there is an implicit intraday interest rate whenever the overnight interest rates differ within an operating day and depending on the intraday time point at which the overnight credit contract was traded. Their empirical results are in line with the expected theoretical findings that the intraday rate curve shows a clear, but low, downward pattern throughout the operating days in 2003 and 2004. Moreover, this question may be also very important from the central bank point of view which is interested to monitor the implications of its different policies in the provision of intraday credits. The objects of interest are credits with shorter maturity than one day.

Baglioni and Monticini (2010) redo this analysis for 2007, using hourly means, to compare the intraday curve before and after the outbreak of the financial crisis. They find some clear signals for a downward trend of the intraday interest rate especially after the outbreak of the financial crisis in 2007.

Baglioni and Monticini (2013), using a slightly different concept for the estimation of the intraday rate curve, also find a higher downward trend of the intraday interest rate after the onset of the financial crisis in 2007 and even more after the collapse of Lehman Brothers in 2008.

Furthermore, Gabbi et al. (2012) analyze the intraday behavior of interest rates, using a sample from 1999 to 2009 . They find a stable intraday interest rate before the crisis and a significant downward trend after the outbreak of the financial crisis. According to Gabbi et al. (2012), this effect becomes larger after the collapse of Lehman Brothers.

Other researchers, e.g., Raddant (2014) analyze the intraday interest rate on the e-MID, using a complex construct for the depended variable based on interest rates. First, the results of such analyses are not clear from both the theoretical as well as the practical point of view because the dynamic of such a complex constructed variable is unknown and not directly observable on the market. In addition, such analyses may also attract little interest from the practical point of view in terms of applying trading strategies.

Moreover, other intraday interest rate constructs, including the papers by Abbassi et al. (2017), using secured funding data, Jurgilas and Žikeš (2014) and Merrouche and Schanz (2010) in the UK, and Furfine $(2001,2002)$ in the US, present works for the modeling and the analysis of the intraday interest rate.

However, their econometric models are still based on a linear regression. That means that their estimates of the term structure of interest rates are locally linear even though they indicate some nonlinear intraday term structure.

Although, Gabbi et al. (2012) also claim, that the shape of the intraday term structure may be only linear. This fact can also be observed by just plotting the interest rates and the time of the credit transaction of different days. One can observe that the assumption of monotone falling interest rates is violated and that days with an increasing, decreasing or U-shaped interest rates structure can be observed. Based on their argumentation and in our opinion, it is quite intuitive to assume that this SIYC is a nonlinear function in maturities, which can be modeled by the NSM. Hence, the capability of the NSM to model the SIYC lies within the research focus of this paper. Thus, in contrast to these studies which use linear models or linear regression estimation methods for the analysis of the intraday interest rates as the depended variable, we introduce a novel concept of intraday maturity so that 
the analysis of the intraday interest rate can be done through the concept of the yield curve where the credit maturity plays a major role. Hence, this concept and the underlying mathematical concept for the analysis of the intraday interest rates on an interbank credit market via SIYC-s are firstly presented in this paper. Moreover, the above mentioned studies do not use tick-by-tick data but focus rather on intervals of time (e.g., one hour) during their data sample. From the practical point of view and for trading purposes, it is more important to consider real-time in terms of tick-by-tick data which we use in this paper. Additionally, those studies do not estimate different curves for every single day, but for rather large time horizons. So these concepts might be based on the unrealistic assumption that the yield curve does not differ over the considered time period. However, the opposite is the case and our methodological concept is suitable for the analysis of such day-by-day effects as well. Hence by comparing with previous studies, researchers as well as practitioners can benefit from our study twofold: first by applying a more advanced non-linear model for the novel concept of the SIYC-s and second, from the more flexible analysis and use of available information for every single day.

After providing the method to analyze the intraday SIYC on an interbank credit market, the second core research objective is to analyze the effects on the interbank credit market before, during and after the financial crisis of 2007. To analyze these effects, we split the data into four periods and redo the same analysis for each period separately.

The estimated intraday SIYC-s show a dramatic change in the intraday dynamics during the turmoil, whereas, prior to this turmoil, the intraday dynamics had been quite flat, signaling that the interest rate was not expected to change significantly during the day. After the last intervention of the ECB in the sample on the 13th of May 2009, the dynamics of the intraday interest rates become almost flat again. This can be seen as a result of the disappearance of liquidity in consequence of the provision of cheap and almost riskless liquidity through the ECB. These facts can be only observed based on the analysis of the SIYC-s and were not highlighted in prior studies on the e-MID market, or on interbank credit markets in general.

In this context, we do the analysis of the empirical fit of the model to evaluate its empirical relevance for the modeling of the intraday yield curves. To our best knowledge, our analysis presents the first estimation of the yield curve on the intraday frequency for the e-MID using the nonlinear NSM (and for an interbank credit market in general). As already mentioned, the further goal of our paper is to find out whether the differences in the estimates of the SIYC-s for the different periods with focus on the financial crisis are statistically relevant. Significant differences in the model fit can detect systematic differences in the behavior of the market participants and, thus, provide the evidence of the state of the market signaling for a possible financial crisis. To this end, we will use the NSM for the analysis of SIYC in the e-MID based on observable intraday interest rates due to the model's theoretical and practical importance and simplicity.

Lastly, we do this analysis in the light of very practical purposes. This is, to let our analysis and results serve for practical uses, such as the direct estimation and forecast of the intraday interest rates on the interbank credit market at high frequencies for tick-by-tick data so banks can optimize the trading strategies on the interbank credit market as well.

This paper is organized as follows: In Section 2, we briefly introduce the e- MID market. In Section 3, we postulate our working hypotheses. In Section 4, we present the NSM and the estimation technique which we apply. In Section 5 , our data set is presented along with the descriptive statistics for the estimation of the SIYC-s. The statistical evaluations of our estimates are presented in Section 6. In Section 7, we interpret the estimated yield curves from an economic point of view. Additionally, we present implications of our estimated SIYC-s in Section 8. In Section 9, we conclude our paper.

\section{The e-MID}

The e-MID was founded in 1990 as an initiative of the Bank of Italy. Initially, the e-MID was used exclusively for the euro interbank market. However, its activities expanded 
rapidly into other currencies, including the U.S. dollar, the British pound, and the Polish zloty (Brunetti et al. 2010).

The trading volume and number of transactions increased systematically in the e-MID until the outbreak of the global financial crisis. Before the crisis, on any dealing day, about 450 transactions were completed with an average credit volume of 5.5 million euros per transaction (Gabbi et al. 2012).

The trading period in the e-MID begins daily at 08:00 a.m. and ends at 06:00 p.m. $(\mathrm{UTC}+1)$. During this period, credits ranging from a minimum amount of EUR 50,000 and a maturity of one day to credits with a maturity of up to one year are traded. As already stated, the segment of overnight credits represents about $90 \%$ of all transactions, in terms of both absolute number of transactions and trading volume, in general as well as in our sample.

Various lending institutions, including banks and investment companies, are allowed to actively participate in the e-MID. To do so, these institutions must meet several requirements: The net capital of credit institutions, including banks, must be a minimum of USD 10 million or its equivalent in another currency, and for investment companies it must be 300 million euros or its equivalent in another currency. Before the outbreak of the global financial crisis in 2007, 246 institutions from 29 countries of the European Union and the United States were members of the e-MID. Among them were 30 central banks and two finance ministries, which worked as market observers, and 108 domestic (Italian) and 106 international banks as active market participants (Gabbi et al. 2012). For a detailed description and explanation of e-MID see e.g., Gabbi et al. (2012) or Brossard and Saroyan (2016).

The functioning of the e-MID can be described as simple and transparent. The bank acting as quoter establishes the credit inquiries, both lending and borrowing credit orders, in the order book of the e-MID, which can be monitored by all market participants in real time. The identity of the quoter bank and the credit amount, the interest rate, the credit term, and type of credit application (credit borrowing or credit lending) are revealed. If the order is a lending order, the quoter bank shows a cash surplus. If it is a borrowing order, the quoter bank reveals a liquidity demand. The bank that operates as an aggressor has the option of choosing a credit request from the order book and arranging a credit. After the aggressor bank identifies a credit request from the order book as appropriate, the credit transaction is nearing completion. The e-MID system again allows both market participants to negotiate the specifications of the credit. Furthermore, the quoter bank has the right to reject the lending order, while the aggressor has the right to abort the order once the counterparty is known. Although the data do not show the number of neglected credit transactions. If the transaction is executed, it is automatically processed by the payment system and the order book is automatically updated (Iori et al. 2012; Brunetti et al. 2010).

This market mechanism is a peculiarity of the e-MID and offers an important advantage over other interbank credit markets: the market can be described as completely transparent and reliable, with the possibility for all market participants to monitor the trading and the interest rate developments in real time (Iori et al. 2012; Brunetti et al. 2010).

However, the complete transparency of the e-MID may also be a pitfall, especially during times of a financial crisis. Because times of turmoil are marked by a high degree of uncertainty about bank liquidity, many banks avoid trading in transparent markets in order to hide potential liquidity shortfalls. This complete transparency could explain the phenomenon that the volume and number of transactions and the number of active market participants in the e-MID decreased steadily after the onset of the financial crisis in 2007 (Iori et al. 2012).

\section{Working Hypotheses}

Baglioni and Monticini (2008) claim that the intraday yield curve shows a linear downward pattern throughout the operating day in 2003 and 2004, and then even more clear afterwards in 2007, especially after the outbreak of the financial crisis in August (see 
Baglioni and Monticini 2010). The objects of their interest are credits with shorter maturity than one day on the e-MID. The authors claim that there is an implicit intraday interest rate whenever the overnight interest rates differ within an operating day and depending on the intraday time point at which the overnight credit contract was traded. Their analysis and results support the assumption that the intraday interest rate shows a clear downward pattern during a trading day. This is explained by the theoretical assumption of the risk premium within intraday credits and the cost of borrowing from the central bank in 2007 (Baglioni and Monticini 2010). However, the e-MID belongs to the class of electronically organized financial markets where the price process is mainly influenced by the unobserved process of incoming news.

Affinito (2012) suggests that in times of financial stability banks select their counter partners based on observable as well as testable monitoring factors, including different credit ratings. This selecting mechanism changes in times of a financial turmoil. After the outbreak of the financial crisis in August 2007, the borrowing banks are selected mainly based on preexisting relationships and non-observable risk indicators. Moreover, Angelini (2008) finds out that, when the central bank announces a rate change, the market reacts and revises the expectations about the overnight rate. Furthermore, he suggests that the overnight rate can be changed not only by the central bank but also by other macroeconomic news. Baglioni and Monticini (2013) also argue that the differences in the intraday interest rate, which become more relevant after August 2007 and after September 2008, may be interpreted also by the changes of the spread between the EURIBOR and EONIA rates, reflecting incoming news. Hence, we will assume that the price building process on the e-MID is also driven by incoming relevant news, as it is the case on every financial market.

In this context, the efficient market hypothesis of Fama (1970) postulates that the movements of financial prices essentially depend on a 'news arrival process' whereby incoming news are immediately incorporated into the asset prices in an unbiased way. Several empirical works provide the evidence that news of monetary variables (Pearce and Roley 1983; Hakkio and Pearce 1985) and of real economic variables (McQueen and Roley 1993; Birz and Lott 2011) are relevant in the price building process of asset prices.

The evidence of the relevant impact of news on the volatility of stock prices is overwhelming, while the impact of bad news should be even stronger (e.g., Engle and Ng 1993; Bomfim 2003; Brenner et al. 2009). However, the condition is that the news are somehow unknown or to some extent not anticipated at the time the news arrive. Hanousek et al. (2009) provide the evidence of spillovers caused by news through different markets while Plummer and Tse (1999) and Caporale et al. (2014) show that volatility-spillovers with bad news have a greater impact than the ones caused by good news. Caporale et al. (2014) base their analysis on newspaper coverage of macro news on stock returns and find out that positive (negative) news have significant positive (negative) effects on stock returns, while the volatility of news has a significant impact on both stock returns and volatility. The effects are shown to be stronger during the financial crisis.

These effects of news on prices and volatilities are more obvious in case of intraday data (Rigobon and Sack 2003; Rangel 2011). In general, bad news increase the volatility more than good news. Those analyses show that the strong nonlinear price process on financial markets is caused by news processes what we can also assume for the interest rate process on the interbank credit market. That means that the assumption of an only monotone falling intraday interest rate is very restrictive and that one should also consider any kind of nonlinear intraday patterns.

Thus, based on the impact of news in the e-MID and the evidence of spill-overs through financial markets, our first working hypothesis is:

Hypothesis 1 (H1). The nonlinear Nelson-Siegel-model is feasible for modeling and estimating the SIYC.

Moreover, Kleinnijenhuis et al. (2013) state that during a financial crisis, the highfrequency trading and high-frequency sentiment analysis is very sensible vis-à-vis much 
more intensive, dramatic and frequent news processes. Therefore, one can assume that there are different states of the markets, or the e-MID in this case. Thus, under the assumption that the more frequent and relevant news during a financial crisis hit the market, our second working hypothesis is:

Hypothesis 2 (H2). During the financial crisis, the usage of the NSM for modeling and analyzing the SIYC becomes even more feasible.

\section{The NSM and the Estimation}

As already stated, modeling the yield curve has been of high interest in the last years. One of the first models that experienced wide use in practice is the NSM. This model was extended and improved in several works (e.g., by Svensson 1994; Diebold and Li 2006), which present relevant models for the yield curve as well. Additionally, different studies focus on the comparison of different yield curve models. e.g., Ioannides (2003) compares the NSM and the Svensson model with other spline based models for the estimation of the yield curve in the UK. Among other aspects, he finds out, that these two models outperform the spline based models for the yield curve estimation in the UK. Due to the novelty and complexity of our methodological concept, we decided in this first study to apply at first the NSM. Other advanced models of Svensson (1994) and Diebold and Li (2006) might outperform the model of Nelson and Siegel (1987) in terms of goodness-of-fit. However, these models achieve much higher degree of nonlinearity, and thus are hard to be optimized, so that further aspects of numerical optimization have to be considered as well. Due to the space limitation in this paper, we cannot consider all three models in this paper, but we aim to do that for tick-by-tick data in the near future. However, as already stated, we use this basic model due to its simplicity and proven empirical performance.

Nelson and Siegel (1987) assume that the forward rate, here denoted as $r$, can be represented by the solution of the following differential equation:

$$
r(m)=\beta_{0}+\beta_{1} e^{\left(\frac{-m}{\tau 1}\right)}+\beta_{2} e^{\left(\frac{-m}{\tau 2}\right)}
$$

where $m$ denotes the maturity of the credit. $\beta_{0}, \beta_{1}, \beta_{2}$ are parameters determined by the initial conditions, $\tau_{1}$ and $\tau_{2}$ are time constraints associated with the equation. This equation generates a wide range of yield curves that take, depending on the value of parameters $\beta_{1}$ and $\beta_{2}$, a monotonous form, a hump with the positive or negative sign, or an S-shape.

The yield to maturity on a specific contract, referred to as $R(m)$, is the average of the forward rate curves and is calculated by the following formula (Nelson and Siegel 1987):

$$
R(m)=\frac{1}{m} \int_{0}^{m} r(x) d x
$$

In this case, the yield curve, which is implied by the model, has the same range of forms. Nelson and Siegel (1987) concluded that this model is over-parameterized and does not converge numerically. They developed a new model that can model empirical yield curves. This model can be represented by the following differential equation:

$$
r(m)=\beta_{0}+\beta_{1} e^{\frac{-m}{\tau}}+\beta_{2} \frac{m}{\tau} e^{\frac{-m}{\tau}}
$$

where $\beta_{0}, \beta_{1}$, and $\beta_{2}$ specify the parameters to be estimated and $\tau$ denotes the time constant. For a given $\tau$, this model is linear. The model (3) includes three terms and is thus modeled by three parameters. The parameter $\beta_{0}$ represents a constant. The second component, $\beta_{1} e^{\frac{-m}{\tau}}$, represents an exponential term which changes monotonically with increasing duration to zero. If $\beta_{1}$ is negative, this term increases monotonically, and vice versa. The last component, $\beta_{2} \frac{m}{\tau} e^{\frac{-m}{\tau}}$, is responsible for the modeling of a positive or negative hump in the yield curve. This term can cause U-shaped yield curves as well. If the maturity $m$ takes high values and strives toward infinity, then the value of the function $r(m)$ approaches the 
value $\beta_{0}$. However, when the maturity approaches zero, then the function value approaches the value $\beta_{0}+\beta_{1}$ (Hewicker and Cremers 2011).

To represent the yield as a function of maturity, Nelson and Siegel (1987) propose integrating model (3) from zero to $m$ and then dividing by $m$. The result of this process is the following equation, which is the linear function by given $\tau$ Nelson and Siegel (1987):

$$
R(m)=\beta_{0}+\beta_{1} \frac{1-e^{\frac{-m}{\tau}}}{\frac{m}{\tau}}+\beta_{2}\left(\frac{1-e^{\frac{-m}{\tau}}}{\frac{m}{\tau}}-e^{\frac{-m}{\tau}}\right)
$$

The limit of the function $R(m)$ is equal to $\beta_{0}$ if the maturity $m$ takes high values and is equal to $\beta_{0}+\beta_{1}$ if the maturity $m$ takes low values, which are the same for the forward rate in model (1), since $R(m)$ represents only the average of $R(m)$ (Nelson and Siegel 1987).

Another possibility, according to Nelson and Siegel (1987), is to detect whether the flexibility of the curves of model (1) reflects the interpretation of the coefficients $\beta_{0}, \beta_{1}$, and $\beta_{2}$, and thus the influence of the short-, medium-, and long-term component for an explanation of the yield curve.

Nelson and Siegel (1987) showed that a variety of empirical yield curves can be modeled based on this model.

Using the MATLAB software, the parameters of the NSM for the SIYC-s were estimated based on Formula (4). This is done by the numerical optimization applying an objective function over $\tau$, whereas the parameters $\beta_{0}, \beta_{1}$, and $\beta_{2}$ are estimated simultaneously in each optimization step using ordinary least squares (OLS). For these purposes, the optimization function "fminbnd" is chosen with the default settings. The "fminbnd" function requires the specification of interval boundaries within which the optimal value is sought for $\tau$. In the context of this paper, the interval limits are set in the range of 0 to 10,000.

To estimate the SIYC-s using the NSM, it is first necessary to define the maturity of each credit. For this purpose, we suggest a new concept of intraday maturity, which has not been used by other researchers until now to the best of our knowledge. The maturity of each overnight credit in the interbank credit market is calculated by the following formula:

$$
m(i)=(18-T(i))+a
$$

where $m(i)$ refers to the maturity of each credit $i$ (measured in hours).

The number 18 represents the time point (06:00 p.m.) when the e-MID closes on every trading day. After this time, no further credit transactions on the day are allowed. $T(i)$ refers to the time at which a credit is assigned.

The market opens on each trading day at 08:00 a.m. If an Italian bank is involved in a credit transaction, the overnight credit must be repaid on the following day at 09:00 a.m. If no Italian bank is involved in the credit transaction, the time of credit repayment is 12:00 p.m. Thus, $a$ in Equation (5) equals one and four in the first and second case, respectively.

The assumption is made that market participants on e-MID use the maximum maturity of ON loans and accordingly repay the loans only on the following day at either 09:00 a.m. or 12:00 p.m. This assumption is based on a microeconomic point of view. The maturity of the intraday loans on e-MID is an implicit variable, namely the time difference between the time of the realized lending transaction and the time at which the loan must be repaid on the following day. It should be noted that it is irrelevant for this empirical analysis whether the loan has already been repaid in advance or whether the maximum term has been exceeded.

The fact is that market participants (also on e-MID) form expectations about future prices based on the amount of information available at the time of the transaction. If the loan has already been repaid beforehand, i.e., not with a maximum maturity, it will either have been due to new information after the time of the credit transaction was conducted or to previous calculations of the respective market participants. The first reason is irrelevant insofar as this new information is not implemented at the amount of information at the time of the lending transaction and therefore cannot influence the behavior of the market 
participants at the given time. The second reason is inconsistent with the hypothesis of efficient markets. It would require an accurate forecast of the future interest rate so that one could profit of it, which, as expected, should not be possible in efficient markets.

In addition, individual reasons of a market participant, such as short-term bridging of the liquidity gap, can cause such behavior. However, such individual information about individual market participants is not implemented in the amount of information that is available on e-MID, and thus this case cannot be relevant from the outset for the analysis, especially since these cases are likely to have a rarity value at most. Therefore, one can determine the maturities of $\mathrm{ON}$ credits in this way and apply these non-linear models. This procedure represents also a major novelty for the empirical analysis of the e-MID market and the interbank credit markets in general. Additionally, we take into account for the maturity of each credit only the time when the market is open and trading of interbank loans takes place. This means that the times when the market is closed, e.g., the time between 06:00 p.m. and 08:00 a.m. or the weekend days are not taken into account for the calculation of the maturity. We calculate the maturity in such way, due to the fact, that in these times the market does not generate further information and thus these times do not have an influence on the price building process at the time of the credit transaction.

\section{Data and Descriptive Statistics}

In our sample, the credits borrowed by the Italian banks represent about $91 \%$ of the total credits. Italian banks also represent the majority of active borrower banks. In addition, many international banks are not active over longer periods in the e-MID. Furthermore, our calculations show that about $96 \%$ of the credits borrowed by Italian banks are also provided by Italian banks (330,078 of 344,445 credits). The remaining $4 \%$ of the credits, taken from foreign banks, can be regarded as noise. Because of these conditions, the SIYC-s were estimated for overnight credits valued between Italian banks. Many other studies, e.g., Hatzopoulos et al. (2015) and Iori et al. (2015) also focus only on transactions between Italian banks.

This implies that the repayment time of each credit extends for one hour because only credits between Italian banks are considered to estimate the intraday yield curve. So, $a=1$ in Equation (5) for all transactions in this paper.

A further restriction of the estimation of the yield curve relates to the maturity of the respective credits. All credits with a maturity of less than two hours were excluded. Thus, the credits taken up after 05:00 p.m. have not been considered in the estimation. This procedure is based on two major facts: First, is because in the period of borrowing from 05:00 p.m. to 06:00 p.m., a relatively small number of credit transactions is observed. Additionally, Gürkaynak et al. (2007) point out that the yield curves behave oddly and should not be estimated based on securities with a very short maturity. This stylized fact is observed due to the lower liquidity of such securities. This is exactly the case in our data set that we observe after 05:00 p.m. until 06:00 p.m. Thus, we estimate the SIYC-s for the maturities in the interval between 08:00 a.m. and 05:00 p.m. The number of credits included in our estimation is about $99.1 \%$ (327,281 out of 330,078 observations). After all restrictions are considered, the SIYC-s are estimated for overnight credits between Italian banks with a maturity of two (minimum maturity) to eleven hours (maximum maturity).

According to Hatzopoulos and Iori (2012), banks on the e-MID behave differently in the pre-crisis period and during the period of the financial distress. We mainly adopt the argument of Gabbi et al. (2012) for the recognition of the key time points in our data sample, which allows us to define four relevant time periods with different economic states on the e-MID.

The first period starts on 03.10 .2005 and ends on 08.08 .2007 , one day before the onset of the global financial crisis, which was caused by disturbances in interbank lending (Green 2011). The second period starts on 09.08.2007, on the onset of the financial crisis and ends on 14.09.2008 (the effective period ends on 12.09.2008, as the next two days are a weekend). The third period starts on 15.09.2008, the day Lehman Brothers collapsed, 
and ends on 12.05.2009. The fourth and last period starts on 13.05.2009, with the ECB's final reduction of the key interest rate in the observation period, and ends on 31.03.2010. In contrast to Gabbi et al. (2012), we construct one more time period after the last ECB intervention. The four periods are shown in Table 1.

Table 1. Presentation of the sub-periods.

\begin{tabular}{lcc} 
Period 1 & 03.10.2005-08.08.2007 & $\begin{array}{c}\text { Period before the crisis } \\
\text { Outbreak of the crisis until the } \\
\text { collapse of Lehman Brothers } \\
\text { Lehman Brothers collapse } \\
\text { until reduction of key } \\
\text { interest rate }\end{array}$ \\
Period 3 & $\begin{array}{c}\text { Key interest rate reduction } \\
\text { until the end of the } \\
\text { observation period }\end{array}$ \\
\hline
\end{tabular}

The main descriptive statistics for the credit transactions between Italian banks in the sample period are summarized in Tables $2-5$.

Table 2. Descriptive statistics: days and observations.

\begin{tabular}{cccccc}
\hline & Whole Sample & Period 1 & Period 2 & Period 3 & Period 4 \\
\hline Number of days & 1641 & 675 & 403 & 240 & 323 \\
Transactions & $(1149)$ & $(473)$ & $(281)$ & $(166)$ & $(229)$ \\
Mean of & 327,281 & 155,992 & 87,427 & 40,483 & 43,379 \\
transactions per day & 283.607 & 328.404 & 311.128 & 242.413 & 190.259 \\
\hline
\end{tabular}

In parentheses: effective days, excluding weekends and holidays.

Table 3. Descriptive statistics: interest rates.

\begin{tabular}{cccccc}
\hline & Whole Sample & Period 1 & Period 2 & Period 3 & Period 4 \\
\hline Mean & 2.837 & 3.023 & 4.037 & 2.164 & 0.380 \\
Std. Dev. & 1.293 & 0.649 & 0.194 & 1.267 & 0.197 \\
\hline
\end{tabular}

Table 4. Descriptive statistics: volume (in Million Euros).

\begin{tabular}{lccccc}
\hline & Whole Sample & Period 1 & Period 2 & Period 3 & Period 4 \\
\hline Mean volume per day & 6384.313 & 8215.736 & 6735.380 & 4849.408 & 3344.431 \\
Mean per Transaction & 22.511 & 25.017 & 21.468 & 20.004 & 17.578 \\
\hline
\end{tabular}

Table 5. Descriptive statistics: maturity (in hours).

\begin{tabular}{cccccc}
\hline & Whole Sample & Period 1 & Period 2 & Period 3 & Period 4 \\
\hline Mean & 6.906 & 6.887 & 6.734 & 7.221 & 7.030 \\
Std. Dev. & 2.576 & 2.618 & 2.571 & 2.471 & 2.497 \\
\hline
\end{tabular}

As we can see, the mean of intraday interest rates, the mean volume per day and the mean volume per transaction drop enormously after the collapse of Lehman Brothers.

This period is seen as the culmination of the financial crisis, where the crisis became even more acute (Lane 2012). This trend is also observable in period 4 . Hence, we can state that our periods 3 and 4 are associated with (and after) the culmination of the financial crisis and its consequences for the interbank credit market, respectively. This fact leads to the conclusion that the system experienced a dramatic change in these two periods compared with the previous two ones. We thus claim that the system changes its state. The fact that the market was in a state of crisis in period 2, but at the same time was still functioning 
normally, can be seen also from the fact that the daily interest rate has a sideways dynamic in this period, i.e., remains at an almost constant level. During these particular periods, the maturity of the credits increases as well compared with periods 1 and 2 . Furthermore we can observe an increase of the average maturity. That mean that the traders seem now to become more active earlier within a day. That can be due to the lower trading volume and the lower number of trades in periods 3 and 4 , and thus to the higher risk in the market. To sum up, periods 1 and 2 refer to the normal state of the e-MID, whereas periods 3 and 4 are recognized as an abnormal state of the market where the liquidity provision is no longer working properly anymore. The period 1 is referred as the pre-crisis period, the periods 2 and 3 are referred to as the crisis periods and period 4 is the after crisis period.

\section{Statistical Evaluation of the Estimates}

We apply the NSM by estimating its parameters and calculating $\mathrm{R}^{2}$ for each single day. Hence, the number of $R^{2}-s$ is equal to the number of days in our data sample. Table 6 presents the descriptive statistics for the estimated $R^{2}$ in the whole sample and for each period. At first, we can state that the goodness-of-fit of the NSM in the empirical estimation of the SIYC-s on the e-MID is quite high. We report an average $\mathrm{R}^{2}$ of 0.3565 in the overall sample. Moreover, based on the t-statistics, $\mathrm{R}^{2}$ seems to be statistically different from zero at the $1 \%$ significance level in the whole sample as well as in each period. ${ }^{1}$ Thus, with respect to our first working hypothesis, we can confirm that the NSM is suitable for the modeling of the SIYC-s on the e-MID.

Table 6. Descriptive statistics for $\mathrm{R}^{2}$ for the SIYC-s estimated by the NSM.

\begin{tabular}{cccccc}
\hline & Whole & Period 1 & Period 2 & Period 3 & Period 4 \\
& Sample & Perion & & \\
\hline Mean & $0.3565^{* * *}$ & $0.3709^{* * *}$ & $0.4242^{* * *}$ & $0.3185^{* * *}$ & $0.2714^{* * *}$ \\
Std. dev. & $0.2049^{* *}$ & 0.2065 & 0.2150 & 0.1920 & 0.1603 \\
t-statistic & 58.8924 & 39.0626 & 33.0735 & 21.3747 & 25.6197 \\
\hline$* *$ Denotes significance at the 1\% level. & & &
\end{tabular}

In the pre-crisis period, an $\mathrm{R}^{2}$ of 0.3709 is achieved, which is also significant at the $1 \%$ significance level. In this period the dynamics of the intraday interest rates are mainly influenced by the uncertainty or the intraday risk premium, as also already stated by Angelini (2000) or Baglioni and Monticini (2008). However, this $\mathrm{R}^{2}$ is much higher than the $\mathrm{R}^{2}$ achieved by both Angelini (2000) and Baglioni and Monticini (2008), of 0.02 and 0.09 respectively, in their analysis for the pre-crisis period. However, in both articles authors use the hourly averages of interest rates on e-MID as the dependent variable, whereas we use the original tick-by-tick interest rates. From a practical point of view, that means that our results are even more interesting for the analysis and the practical use of the SIYC, e.g., for the trading strategies.

Period 2 is characterized with the highest average $R^{2}$ of 0.4242 . The average of the $\mathrm{R}^{2}$ is also here statistically different from zero at the $1 \%$ significance level. This is the period after the onset of the financial crisis. Given the highest average $\mathrm{R}^{2}$, compared with the other periods, indicates that the NSM has the best goodness-of-fit in this particular period. We interpret this empirical result such that the traders in this first period of the financial crisis are influenced by the significant, relevant and more frequently incoming news and are thus forced to systematically and more frequently update their intraday trading strategies. The average $R^{2}$ is also quite higher than the average $R^{2}$ provided by Baglioni and Monticini (2010), of 0.34 from July 11th to August 6th and of 0.21 from August 8th to September 10th, who also state that after the outbreak of the financial crisis the intraday interest rate structure becomes more important and not quite flat like before this event.

In period 3 , the $\mathrm{R}^{2}$ decreases to 0.3185 but remains significant at the $1 \%$ level. After the collapse of Lehman Brothers at the beginning of period 3, traders begin to successively escape the e-MID and the market mechanism appears not to function properly anymore. 
Thus, our previously described change of the state of the market can also be observed by considering the $\mathrm{R}^{2}$. Porzio et al. (2009) state that after the outbreak of the financial crisis, abnormal patterns of volumes and interest rates can be identified on the e-MID. They can only be described as the worries about the quality and the quantity of the liquidity in the market or the much higher degree of counterparty risk. Furthermore, the behavior on the eMID differs from the law of supply and demand so that the lower rate may not immediately mean higher demand in this period. This can be explained by the fact that many lender banks left the market (to other interbank credit markets or hoarded their liquidity), which leads to a high lack in supply for interbank credits on the e-MID (Porzio et al. 2009). In our opinion, this is the reason why the estimated $\mathrm{R}^{2}$ in this period is lower than in the second period.

In period 4 , whereas the market differs even more from its normal state, the $\mathrm{R}^{2}$ decreases further but is still statistically different from zero at the $1 \%$ significance level. At the beginning of this period, the ECB reduces the key interest rate for the last time in the sample period. The ECB has taken over the liquidity provision for the banks. As already pointed out by Gürkaynak et al. (2007), the interest rates and yield curves behave oddly in times of low liquidity. Therefore, we identify this as the reason why the NSM performs in the last period of our data sample not as well as in the previous periods in terms of $\mathrm{R}^{2}$.

Summing up for the whole sample and for all sub periods, we achieve a remarkable high and at $1 \%$ statistically significant $\mathrm{R}^{2}$. Therefore, we cannot reject our first hypothesis.

Furthermore, we can state, that these differences in the $\mathrm{R}^{2}$ are also statistically different from zero at the $1 \%$ significant level. This is confirmed by the results in Table 7 for the two sample $t$-test.

Table 7. Two sample $t$-test of $\mathrm{R}^{2}$ for the SIYC-s estimated by the NSM.

\begin{tabular}{cccc}
\hline & Period 2 & Period 3 & Period 4 \\
\hline Period 1 & $-3.3732^{* * *}$ & $2.8710^{* * *}$ & $6.4037^{* * *}$ \\
Period 2 & & $5.2291^{* * *}$ & $8.9013^{* * *}$ \\
Period 3 & & $2.6497^{* * *}$ \\
\hline
\end{tabular}

*** Denotes significant different means at the $1 \%$.

Regarding our second hypothesis, we can state that the lowest goodness-of-fit is found in period 4 and the best one in period 2; the results of the two sample $t$-test confirms this finding. Thus, the highest likelihood for the correct modeling of the SIYC dynamics via the NSM is in the appearance of the financial crisis as long as the market mechanism may still be intact. In our opinion, the process of more frequent and important incoming news within a day after the onset of the financial crisis causes a stronger systematic impact in the SIYC resulting in the highest $R^{2}$ of the NSM. The second highest $R^{2}$ is found in period 1 where the market is also in the normal state.

In period 3 and 4 , the market is in abnormal state with the successively withdrawn liquidity, which turns into a significantly lower $\mathrm{R}^{2}$ compared with periods 1 and 2 . However, our results from period 1 (outside the crisis) and period 3 (within the crisis) may not be directly compared with each other due to the different states of the market. Therefore, we can neither reject nor confirm our second hypothesis regarding period 3 . This is also the case for period 4 , with the worst results regarding $\mathrm{R}^{2}$. Based on this fact, it can be reasonably expected that the goodness-of-fit of NSM will be worst when the market does not function properly. Given a well working market in the financial crisis, the NSM achieves the highest goodness-of-fit. This is stated through our second hypothesis what means in turn that our second hypothesis cannot be rejected.

\section{Graphical Presentation and Economic Interpretation of the Estimated SIYC-s}

To illustrate the effects on the SIYC-s visually, we provide the graphical presentations of the estimated curves in this section.

The estimated SIYC-s for each trading day and for the entire sample are shown from two angles in Figure 1. One can see flat yield curves before the turmoil; followed mostly by 
quite different and highly nonlinear yield curves until they become flat again at the end of the considered sample period when the ECB takes over the role of the liquidity provider for the e-MID.
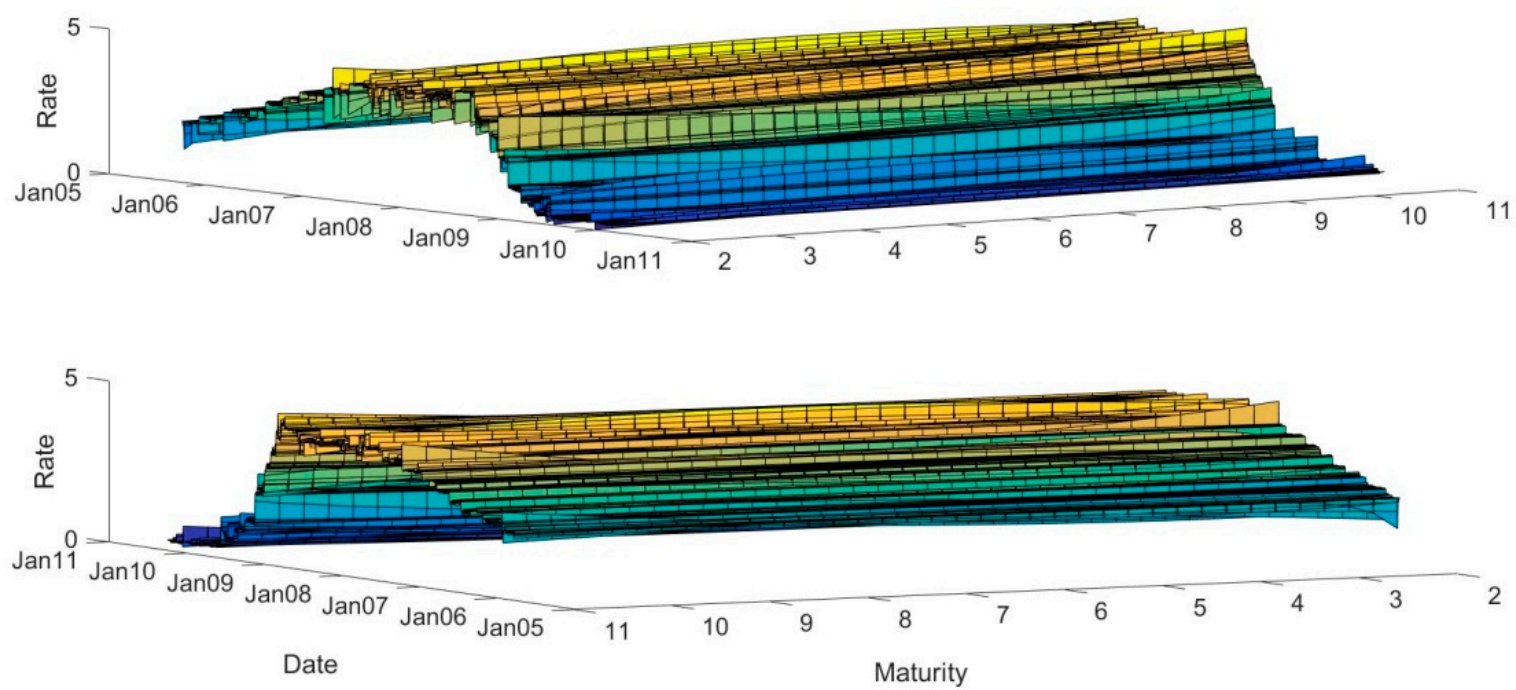

Figure 1. SIYC-s in the whole sample.

The first period under consideration in the e-MID is characterized by a high degree of liquidity. The volume and number of credits between Italian banks are increasing. Moreover, the number of active banks increases during this period. This implies a high degree of confidence in the likelihood of repayment between the Italian banks. Most of the SIYC-s are flat with some small positive and negative intraday tendency. Moreover, on the daily frequency, the daily interest rate follows a positive trend from about $2 \%$ at the beginning of this period to about $4 \%$ at the end. The SIYC-s for the first period are shown in Figure 2.

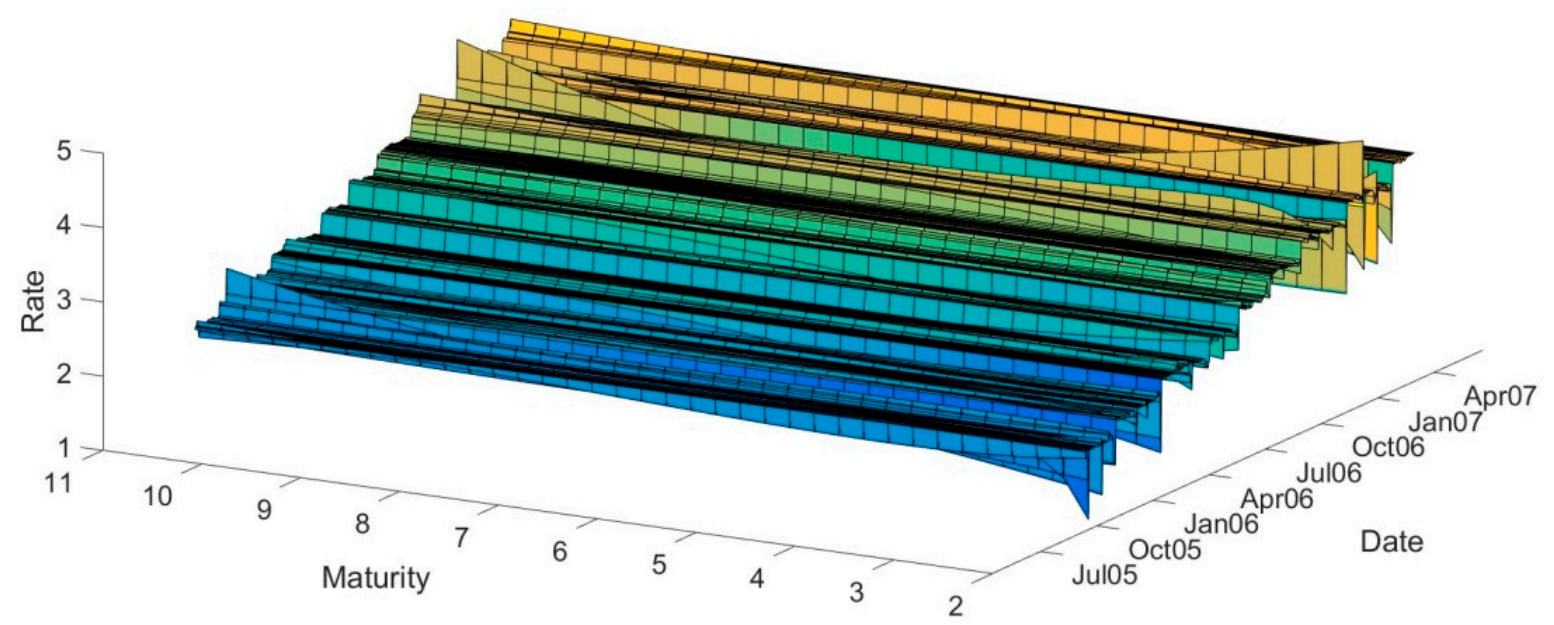

Figure 2. SIYC-s of the e-MID in period 1.

The SIYC-s, with a few exceptions in this period, are quite flat. This implies stable expectations on the intraday frequency in the e-MID that may be caused by a stable global economic development. These findings are also consistent with the findings from Angelini (2000), Baglioni and Monticini (2008) and Gabbi et al. (2012), as we consider a "pre-crisis period".

From the end of January 2007 to approximately mid-February 2007, non-flat and rather monotone decreasing SIYC-s can be recognized. The borrowing in early stages of a 
day (long maturity) is predominantly characterized by a higher interest rate than credits taken in a late stage of the trading day (short maturity). These effects in dynamics of the SIYC-s may be the first sign of higher uncertainties on the intraday basis and may thus be an indicator for a possible upcoming financial turmoil. One can explain it as follows: To calculate the risk of lending, at the beginning of the trading day banks demand higher interest rates for the allocation of a credit. The credit risk is a within-one-day calculation and is higher at the beginning of the day due to higher uncertainties. On the other side, if a credit transaction takes place at a later point in time during the day, the amount of uncertainty for that particular overnight credit is lower and the interest rate decreases: thus, the higher the risk, the higher the intraday interest rate (the risk premium as pointed out by Baglioni and Monticini 2008). However, if some unexpected or new uncertainty, e.g., in form of news, is recognized during the day, traders take this into account for their trading strategy. This can result in a monotone decreasing, increasing or a positive or negative hump in the SIYC. Though, these cases are rarely observed only at the end of this period.

Period 2 is characterized by a high volatility of daily interest rates. The interest rates vary widely between 3.7 and $4.4 \%$. In this period, the beginning of a decrease in the volume and number of credits is observed. The shape of the SIYC-s in this period is characterized by different dynamics which reflect a high degree of uncertainty regarding the expectations of Italian banks. The SIYC-s for the second period are shown in Figure 3.

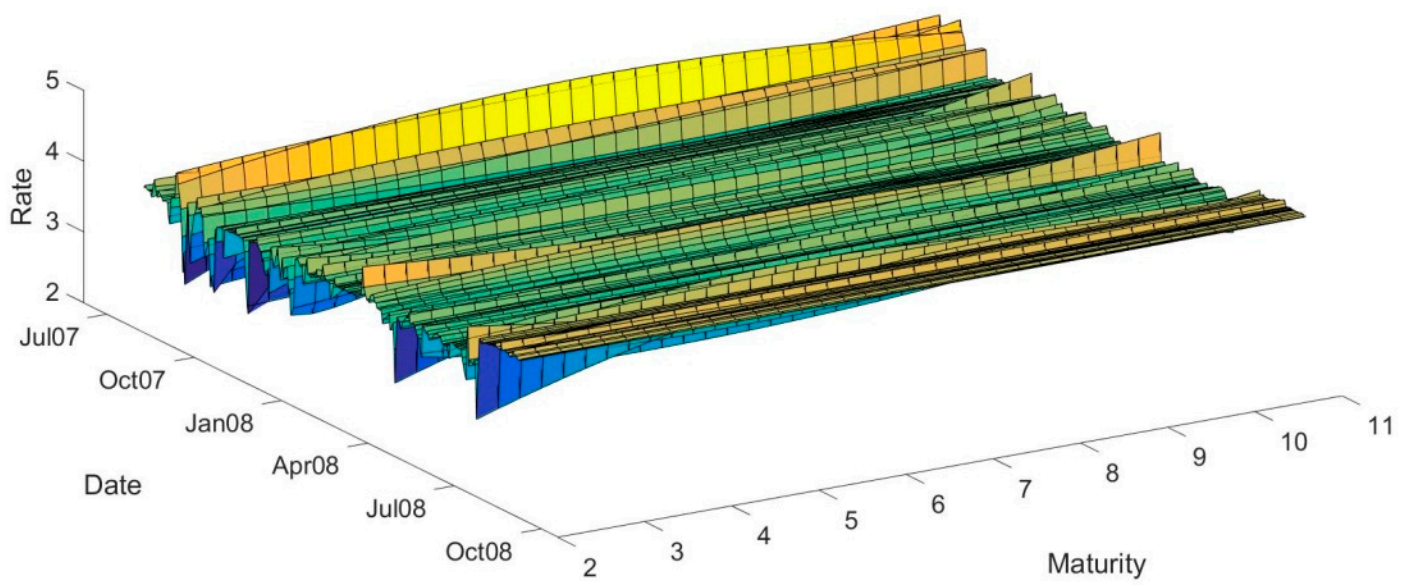

Figure 3. SIYC-s of the e-MID in period 2.

After the outbreak of the financial crisis on the 9th of August 2007, considering higher uncertainties, the creditor banks could not clearly assess within a day the probability of repayment by the borrower banks. There is therefore a loss of confidence between banks in the e-MID (Swiss National Bank 2008). This loss of confidence is likely to be the cause of the slight decline in the volume and number of loans (Porzio et al. 2009). This phenomenon constitutes a major problem for banks, which depend on interbank credits in this period. The decline in liquidity in the market thus made it more difficult to compensate for liquidity constraints and to achieve the individual investment goals (Cappelletti et al. 2011).

Thus, after the outbreak of the financial crisis, further highly nonlinear dynamics in the estimated SIYC-s are clearly visible in our estimates. The high frequency and the quantity of relevant news during this first period of the financial crisis causes these upward and downward sloping SIYC-s and SIYC-s with positive and negative humps alternate quickly over the days. That means that the expectations were highly unstable and diffuse due to the turmoil in the e-MID.

According to the estimates of the SIYC-s, period 2 is the period with higher risk (compared with period 1), which is shown in quickly alternating intraday dynamics. Furthermore, as stated by Baglioni and Monticini (2010), the uncertainty about the availability of funds in the interbank market grew substantially. That means that, e.g., credits with longer maturity are offered at a higher interest rate than credits with shorter maturity 
during a day. Moreover, periods with positive or negative humps were observed as well where participants on the e-MID formed different expectations for the beginning and the end of day compared with the middle of the day, respectively.

On the other side Brunetti et al. (2010) state that, in contrast to the pre-crisis period, where the short-term ECB policies provide liquidity, the unconventional ECB interventions during the financial crisis seem to increase the volatility and the uncertainty in the e-MID market during this period, e.g., on the 9th of August 2007, where the ECB increased the scope of its main refinancing operations by 95 billion euro (Mojon 2010). This phenomenon can also be observed in our estimates in form of alternating nonlinear estimated SIYC-s; after that, the ECB raised the key interest rate for the euro zone in July 2008 to ensure that prices remained stable (Ruckriegel 2011).

Period 3 starts with the collapse of Lehman Brothers. The estimated SIYC-s for the third period are shown in Figure 4. As already stated, this period after the collapse of Lehman Brothers is seen as the culmination of the financial crisis with the highest degree of uncertainty. Thus, the same reasons as in the previous period cause the highly nonlinear alternating forms of the SIYC-s. However, this period is also characterized by the dramatic fall in volume and number of trades on the e-MID. As already mentioned, we assume that the e-MID had entered another state by now. The further consequence is the abrupt negative trend in the interest rate on a daily basis.

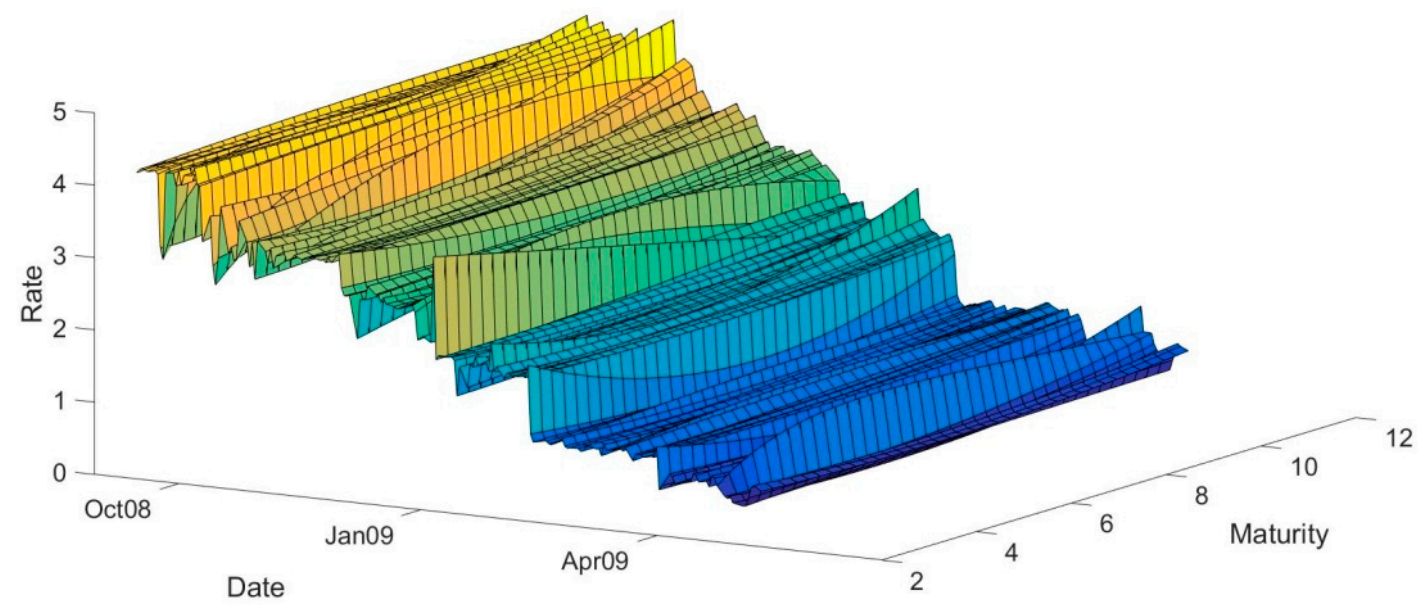

Figure 4. SIYC-s of the e-MID in period 3.

The shapes of the estimated SIYC-s in combination with falling interest rates on the daily frequency can be interpreted in two ways: It may reflect a high degree of uncertainty and negative expectations of the Italian banks in the e-MID, also due to developments in the worldwide financial markets. The bankruptcy of Lehman Brothers led to expectations that a similar loss could also occur among banks in the e-MID. Hence, due to this uncertainty, we can see in the days after the Lehman Brothers collapse that the SIYC-s have different nonlinear shapes paired with a negative tendency of interest rates on a daily frequency. Baglioni and Monticini (2013) and Gabbi et al. (2012) report a dramatic decreasing intraday interest rate after the collapse of Lehman Brothers (higher interest at the beginning of the day). However, our results show that also days with decreasing and increasing intraday interest rates, or positive or negative humps in the estimated SIYC-s, can again be observed, like in period 2. Actually, during the whole period we can observe a lot of days where the SIYC has a positive or negative hump in the estimates of the SIYC, e.g., approximately from the end of October 2008 until the end of November 2008 and from the middle of October 2009 until the middle of December 2009.

During this period, the interest rate follows a negative trend on a daily basis from about $4.3 \%$ at the beginning of this period to a level of about $0.5 \%$ by the end of the period. However, this declining interest rate on daily frequency does not imply a decrease in the 
risk of the granted credits. From our point of view, the opposite was the case. The lender banks could estimate the probability of repayment by the borrowing counter partner only to a very limited extent. The banks were further concerned that systemic risks could lead to contagion (Fricke and Lux 2015). Thus, there was also a high loss of confidence among Italian banks. In this period, even more banks leave the market and the volume and the number of trades drops significantly (Cappelletti et al. 2011). Banks may invest their cash surpluses in other markets, to deposit them with the ECB at the deposit rate, or to hoard them. This resulted in a massive decline in the volume and number of credits.

The fourth period starts on 13.05.2009 with the last ECB intervention in the sample period and ends on 31.03.2010 in our sample. The estimated SIYC-s for the fourth period are shown in Figure 5. As we can see, after the last key interest rate change during the observation period, the interest rate increased for a short period from about 0.5 to $1 \%$. This implied a slight gain in confidence of Italian banks and caused a short-term increase in the volume and number of credit transactions between Italian banks. This trust-gain, however, was not of great duration. This in turn resulted again in highly nonlinear dynamics in the SIYC-s over subintervals.

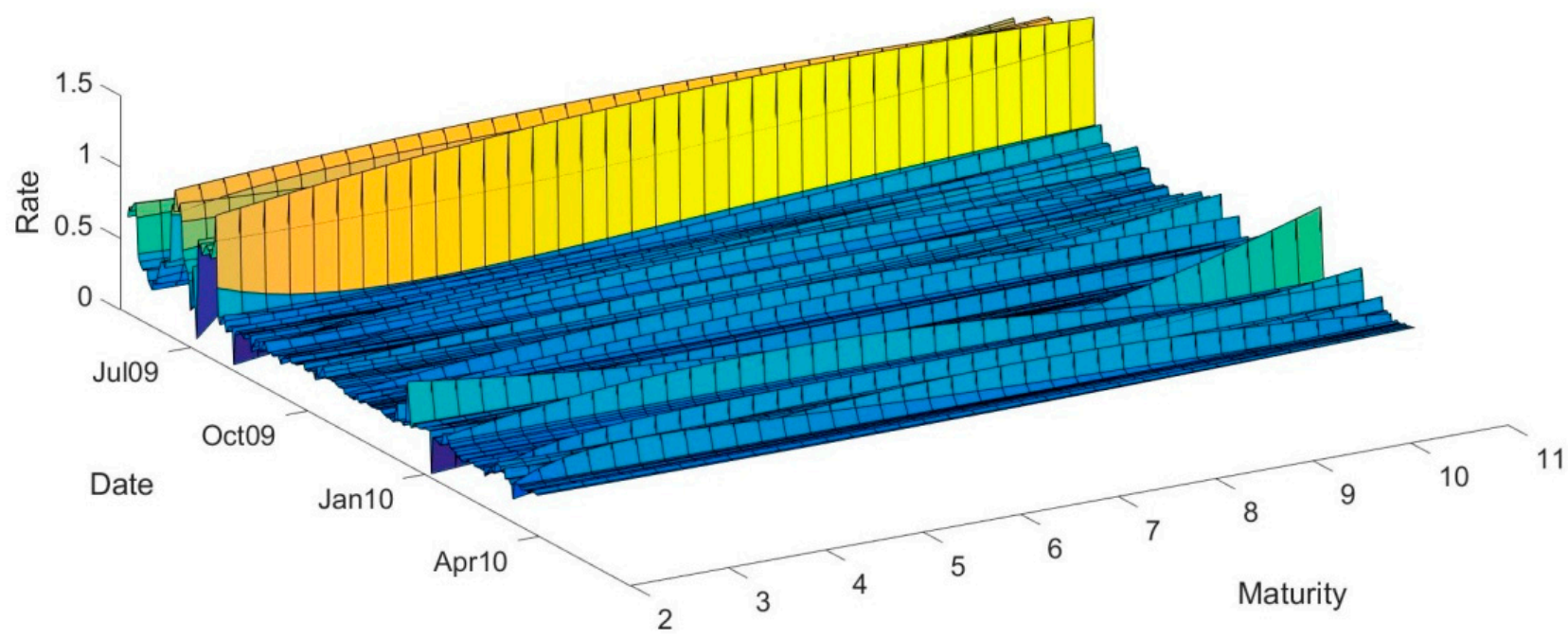

Figure 5. SIYC-s of the e-MID in period 4.

Moreover, in this period dynamics, with the market still in an abnormal state, SIYC$\mathrm{s}$ show different types of shapes, indicating again diffuse expectations and a different behavior of participating banks in the e-MID with respect to the intraday dynamics of interest rates.

The Italian banks with a cash surplus may either continue to invest more in other markets, to deposit them with the ECB or to hoard them. The banks with a credit need could borrow funds at zero risk at a very low interest rate directly from the ECB. Due to this fact, the number of credit transactions and the volume are on the lowest level and the e-MID becomes less system relevant.

Based on these findings, we strongly believe that one must move away from the assumption that only few variables have an impact on the intraday interest rates on the e-MID market. Additionally, one must move away for the perspective of monotone falling interest rates on the e-MID market. The intraday yield curves may be alternating, based on the price building process of each day. This price building process changes each day since it is influenced by the nice incoming process. So, based on these arguments we can state that, the slope of the yield curve and the hump (positive or negative) may change among different days, when the price building process changes. Here, we point out that by introducing our concept of the intraday maturity for the analysis of the SIYC-s with intraday data, on the one side, and the analysis of yield curves for bonds and credits on the lower frequencies and the macro level, on the other side, these are very similar based on 
the mathematical concept. However, from the point of view of the economic interpretation, there are differences. Whereas the maturities for bonds and credits on low frequencies lie, e.g., between one month and up to 15 years, may be overlapping with specific periods of business cycles. That means that yield curves on such frequencies may be correlated to some determinates of business cycles and thus include some systematics. It is well-known that during economic crises, the yield curve has a downward trend. However, regarding the dynamic and the shape of the SIYC-s on intraday frequencies, it only depends on determinants and the information processes within a day. Therefore, the SIYC-s based on intraday frequencies might have an upward or downward trend, be U-shaped, or be flat during the period of an economic crisis and any other period on such low frequencies. That is exactly what we also can observe and commit by taking look at the Figures 2-4.

According to Hatzopoulos and Iori (2012), there are two "natural" timescales in the network of the e-MID. The one timescale is set by the maturity of the credit transactions, mostly overnight, and the other one is based on the monthly deposit of minimum liquidity reserves at the central bank, the so-called reserve maintenance period, which is equivalent to one calendar month or around 23 business days. In each reserve maintenance period, the levels of the minimum reserve are calculated based on each bank's balance sheet (Hatzopoulos et al. 2015).

The consequence is that the SIYC has regularities within the meaning of seasonal influences that affect the level of the yield curve. In general, the participants in the e-MID align their activity to these dates. Thus, there are clear monthly seasonal impacts and dynamics caused by these requirements. In our opinion, this is also the reason why the estimated SIYC-s seem to be very erratic over the considered days. In their estimates, Baglioni and Monticini (2013) exclude the last days of the maintenance period due to jumps in the interest rate on these particular days in each month.

Thus, to graphically present the estimated SIYC-s without the seasonal influence, we calculate the smoothed SIYC for each day using a moving average process of 23 days in the entire observation period.

The smoothed SIYC-s are presented in Figures A1-A4 in the Appendix A. So, we can see the before mentioned effects on the SIYC-s even better. In order to exclude the maintenance period, further research must be conducted. Our analysis may be a starting point for that kind of analysis on the intraday frequency.

\section{Implications of the SIYC Estimation}

After the SIYC was interpreted from an economic perspective in different periods, the question arises whether and what economic implications can be derived based on the SIYC-s from the e-MID.

The first implication relates to the borrowing of overnight credits by Italian banks on the e-MID. The estimated SIYC-s may allow the participants on the e-MID to recognize opportunistic trading strategies in sense to determine the optimal point in time with a low intraday interest rate, or alternatively, to be able to forecast the intraday time with a high intraday interest rate. This is particularly apparent just before and after the outbreak or in the middle of the financial crisis, since highly nonlinear dynamics exist in these times in the SIYC-s for individual days in the e-MID. Through consideration of the estimated SIYC-s, one can see that interest rate differentials of $1 \%$ are possible within one day.

Additionally, the ECB can benefit from the consideration of the empirically estimated intraday SIYC as well. Since the interbank credit market is the first transmission channel of monetary policy, the ECB can assess banks' expectations on interbank credit markets and observe the effects of their actions on those markets, like the consequences of a reduction or a rise in the key interest rate. Through such evidence based on the estimated SIYC-s, the ECB may be able to choose the optimal timing of its actions and thus generate the best results regarding this specific interbank credit market. For specific suggestions of actions for the central banks during the financial crisis see, e.g., Brunetti et al. (2010). 


\section{Conclusions}

The aim of this paper is to propose the concept of the SIYC and its estimation method. The SIYC-s were estimated for the e-MID, a fully transparent interbank credit market using the NSM in the period from 03.10.2005 to 31.03.2010. We use the data sample until this date, since after 2010 the market becomes even more illiquid, meaning that the number of transactions on the e-MID becomes even lower. After 2010, the main provision of liquidity is given by the ECB and the interbank credit markets become less relevant (Barucca and Lillo 2018). This estimation of the SIYC on an interbank credit market in this paper presents a novel step in analyzing the SIYC-s.

Our results show that the modeling and estimation of SIYC using the NSM is feasible and attractive. These results can deliver fundamentals for the optimization of trading strategies of participants on the interbank credit market.

At the beginning of the financial crisis until the collapse of Lehman Brothers, the goodness-of-fit of NSM is the highest, and thus the intraday SIYC-s experience the highest systematic impact. In this time period, the high risk due to the loss of confidence influences significantly the dynamic of the intraday interest rates, as reflected in the highly notable estimates of the SIYC-s. After the collapse of Lehman Brothers and the last ECB intervention, the change of the state of the system occurs, which becomes evident in the light of the lower volume and number of trades. In period 3, the goodness-of-fit becomes lower than in the previous period but remains remarkably high and statistically different from zero at the $1 \%$ significance level. This quite abnormal state worsens in the next period after the last ECB intervention (period 4) with the lowest volume and number of trades per day. The consequence is that the goodness-of-fit of the NSM at this point in time is the lowest, but is still statistically different from zero at the $1 \%$ significance level.

Our results provide one more interesting finding, namely that shortly before the outbreak of the financial crisis on the 9th of August 2007 and before the Lehman Brothers bankruptcy on the 15th of September 2008, the estimated SIYC-s were indicating different shapes of nonlinear SIYC-s. Such SIYC dynamics may be understood as indicators of an impending crisis in case of the normal state of the e-MID. This implication will deserve a more detailed analysis in our future work.

Finally, after 31.03.2010 (sample end) with the outbreak of the European financial crisis in 2010 (Moro 2014), the ECB took further measures to stabilize the financial system in Europe. These measures included further liquidity provisions for banks with short term liquidity demands. For the e-MID, this had the consequence that the liquidity was successively withdrawn (Barucca and Lillo 2018). Regarding the ECB's impact, one can expect that the ECB will at some point in time in the future retrovert to its normal state of business and will consequently stop providing cheap liquidity by increasing the leading interest rate. From that time onwards, the e-MID may again become a relevant interbank credit market for the financial system. We thus expect that the NSM will again have a significantly better goodness-of-fit in accordance with these facts.

Our analysis will be extended using other models, such as those presented by Svensson (1994) and Diebold and Li (2006). The Svensson (1994) model is an extended version of the NSM. Here a fourth term is added, based on which a second hump in the yield curve can be modeled. Diebold and Li (2006) based their work on the original NSM where the parameters of the model are assumed to be time-varying and Diebold et al. (2006) extend this model by the use of the Kalman filter. That will be our next research focus.

Author Contributions: Both authors contributed the same amount of work to this article. All authors have read and agreed to the published version of the manuscript.

Funding: This research received no external funding.

Data Availability Statement: Restrictions apply to the availability of these data. Data was obtained from e-MID SIM SpA and are available from the authors with the permission of e-MID SIM SpA. 
Acknowledgments: We would like to thank the participants of the 1st international conference in finance and economic policy (ICOFEP) and the participants of the 22nd International conference in macroeconomics and international finance (ICMAIF), for their for helpful comments

Conflicts of Interest: The authors declare no conflict of interest. We wish to confirm that there are no known conflicts of interest associated with this publication and there has been no significant financial support for this work that could have influenced its outcome. We confirm that the manuscript has been read and approved by all named authors and that there are no other persons who satisfied the criteria for authorship but are not listed. We further confirm that the order of authors listed in the manuscript has been approved by all of us. We confirm that we have given due consideration to the protection of intellectual property associated with this work and that there are no impediments to publication, including the timing of publication, with respect to intellectual property. In so doing we confirm that we have followed the regulations of our institutions concerning intellectual property. We understand that the Corresponding Author is the sole contact for the Editorial process (including Editorial Manager and direct communications with the office). He is responsible for communicating with the other authors about progress, submissions of revisions, and final approval of proofs. We confirm that we have provided a current, correct email address which is accessible by the Corresponding Author and which has been configured to accept email from Demertzidis@unikassel.de.

\section{Appendix A Smoothed Estimated SIYC-s}

In this Appendix, we present the smoothed estimates of the SIYC-s.

As already stated, most of the previous studies estimate the intraday yield curve for their whole sample based on hourly averages. From the point of view of the order book analysis, this can actually be seen as the estimation of the intraday seasonality (Hautsch and Jeleskovic 2008). One usually adjusts the data from the intraday seasonality in the first step to analyze the adjusted data in the second step (Hautsch and Jeleskovic 2008). Furthermore, the estimates in their analysis is only one regression curve for all days, or for two different periods as in Baglioni and Monticini (2010).

The smoothed SIYC-s in this paper may be seen as a kind of a dynamic version of the estimated intraday yield curve, comparable to the results from the previously mentioned studies of Angelini (2000), Baglioni and Monticini (2008), Baglioni and Monticini (2010) and Baglioni and Monticini (2013) due to the fact that the smoothing is done based on the single estimated SIYC-s with a window length of 23 days. That means that we calculate the SIYC over the intraday time points based on the estimated parameters of the NSM for certain maturities. Finally, the smoothed intraday interest rate at each point in time is the average over the 23 estimated intraday interest rates, in the middle of the window respectively. The smoothed estimated SIYC-s are shown for each period in Figures A1-A4.

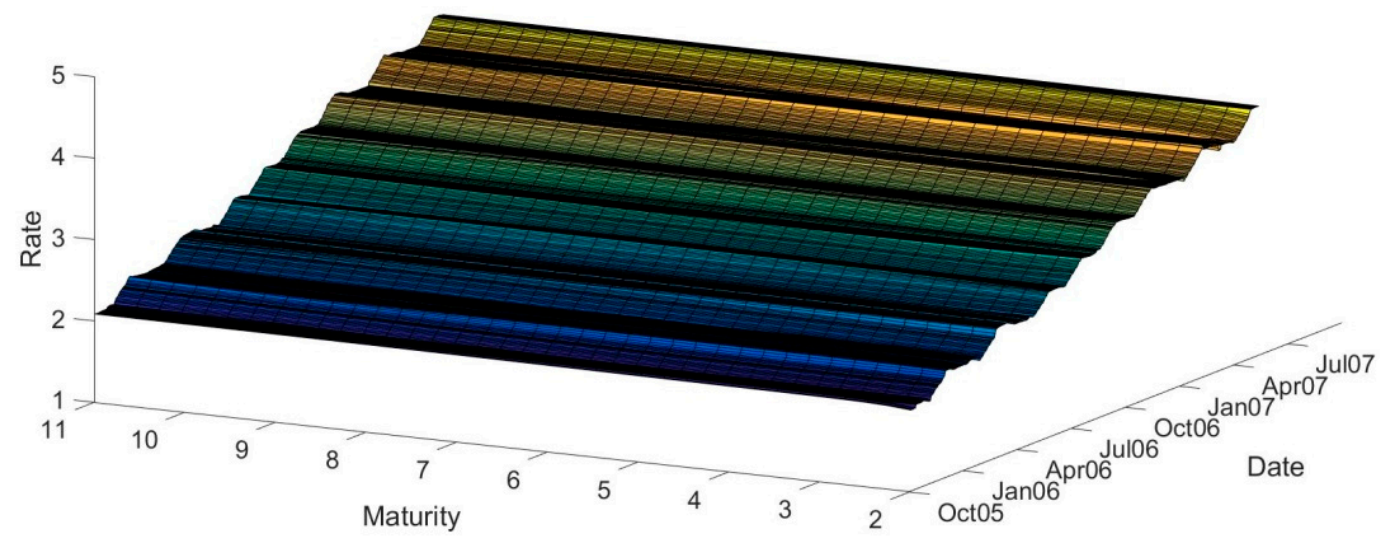

Figure A1. Smoothed SIYC-s of the e-MID in period 1.

The estimated SIYC-s in period 1 show some negative trend during the day. Credits with a higher maturity are characterized with a higher interest rate and vice versa. This 
negative trend within a trading day becomes more obvious before the outbreak of the financial crisis during the time between May and August 2007.

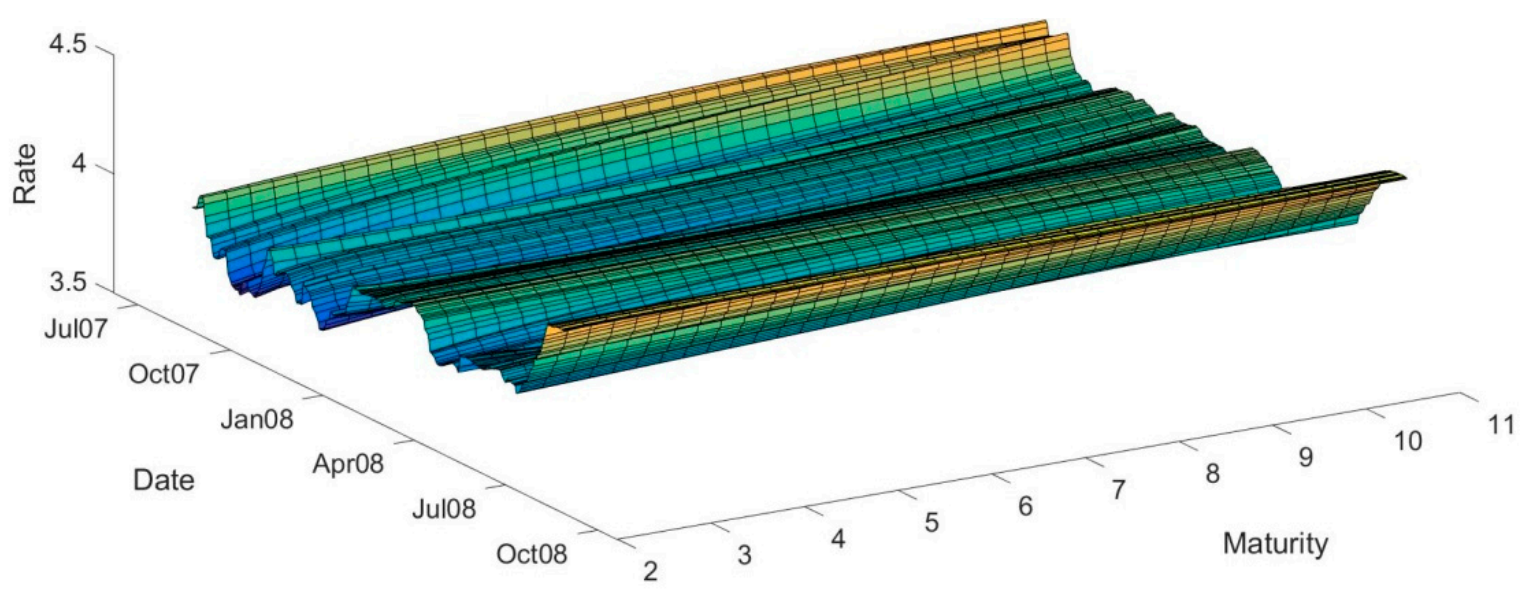

Figure A2. Smoothed SIYC-s of the e-MID in period 2.

After the outbreak of the financial crisis in August 2007, the dynamics of the estimated SIYC-s change dramatically. In the smoothed SIYC-s we can also see that SIYC-s with a positive or negative trend and a positive and negative U-shape are alternating. This phenomenon is a clear signal of the great uncertainty that hit the market participants in this particular period.

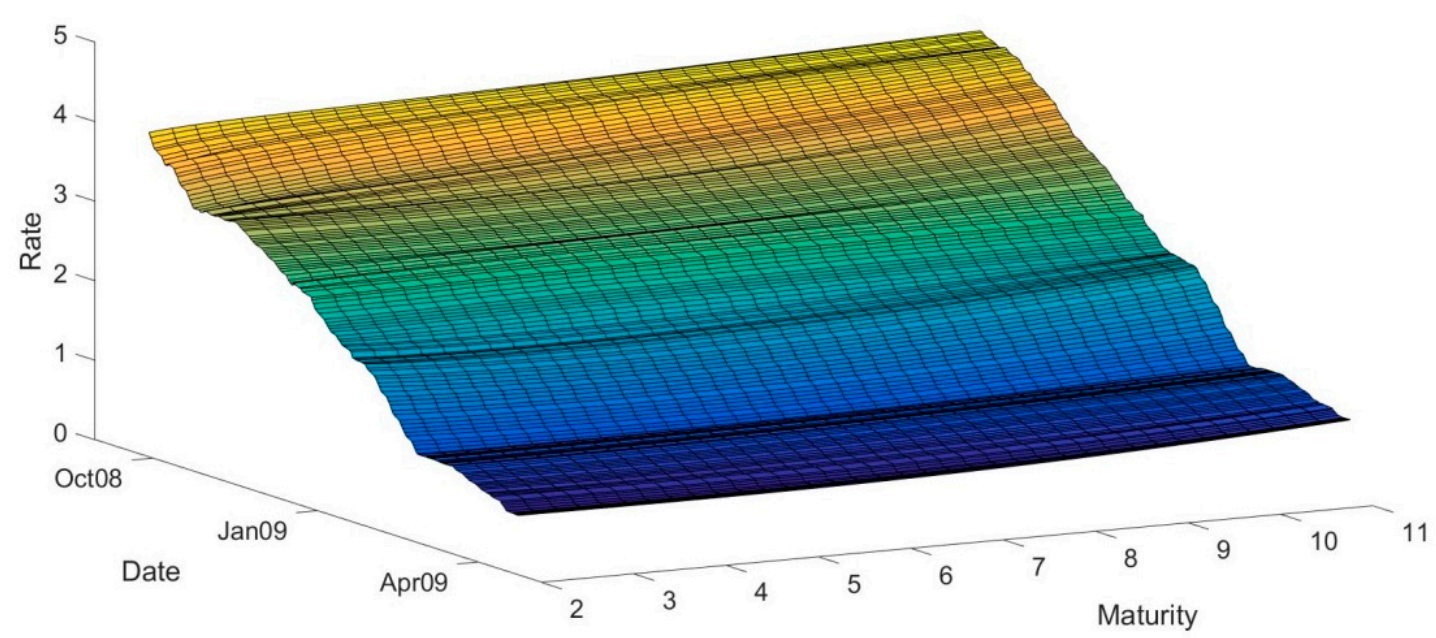

Figure A3. Smoothed SIYC-s of the e-MID in period 3.

The estimated SIYC-s in period 3 show clear different dynamics. Between the collapse of Lehman Brothers and October 2008, a clear downward trend is visible. In November 2008, the SIYC-s have a U-shape and are followed SIYC-s with a clear upward trend up to January 2009. After January 2009, the dynamics of the SIYC-s change, again, to a U- shape. After February 2009, we again see some downward trends in the SIYC-s. As already stated, these quickly changing dynamics emphasize the great uncertainty during this period when the financial crisis became more acute. 


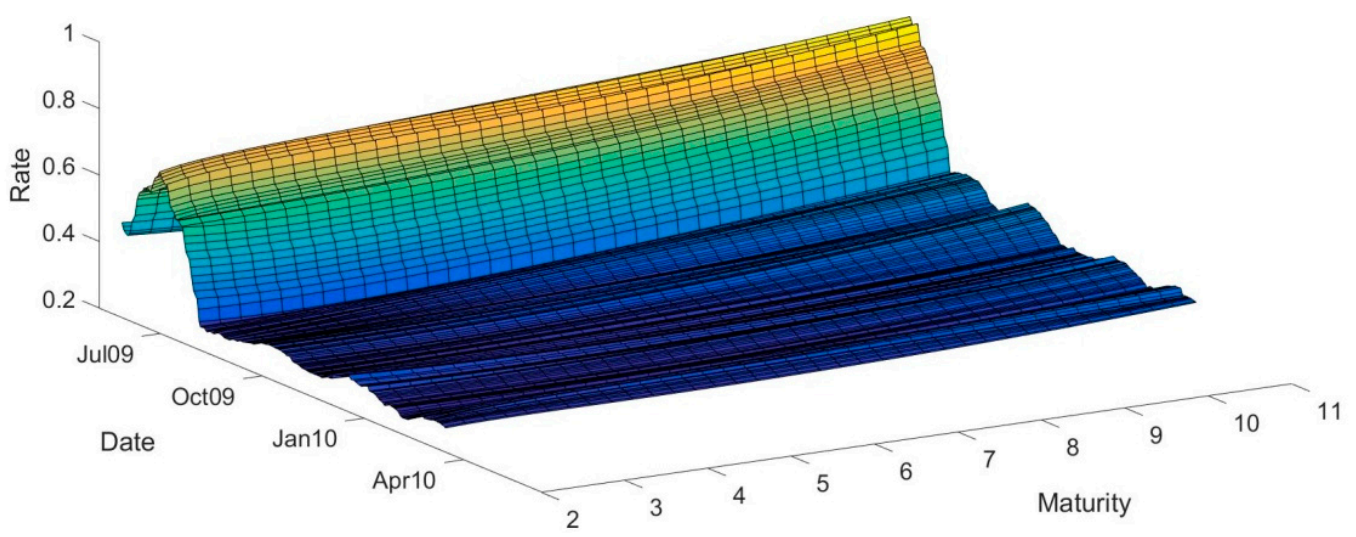

Figure A4. Smoothed SIYC-s of the e-MID in period 4.

After the last intervention of the ECB in the sample period, we see that the interest rate rises from 0.4 to $0.6 \%$ for a small time period. During this period, the estimated SIYC show a clear downward trend up to November 2009. After November SIYC with a U- shape are clearly visible.

\section{Notes}

1 Given a quite high number of observations, we can apply the $t$-test for these purposes due to asymptotic properties of the $t$-test.

\section{References}

Abbassi, Puriya, Falko Fecht, and Johannes Tischer. 2017. Variations in market liquidity and the intraday interest rate. Journal of Money, Credit and Banking 49: 733-65. [CrossRef]

Affinito, Massimiliano. 2012. Do interbank customer relationships exist? And how did they function in the crisis? Learning from Italy. Journal of Banking and Finance 36: 3163-84. [CrossRef]

Afonso, António, and Manuel M. F. Martins. 2012. Level, slope, curvature of the sovereign yield curve, and fiscal behavior. Journal of Banking and Finance 36: 1789-807. [CrossRef]

Aljinović, Zdravka, Tea Poklepović, and Kristina Katalinić. 2012. Best fit model for yield curve estimation. Croatian Operational Research Review 3: 28-40.

Ametrano, Ferdinando M., and Marco Bianchetti. 2009. Bootstrapping the Illiquidity: Multiple Yield Curves Construction for Market Coherent Forward Rates Estimation. In Modeling Interest Rates. Edited by F. Mercurio. London: Risk Books, Incisive Media.

Ang, Andrew, and Monika Piazzesi. 2003. A no-arbitrage vector autoregression of term structure dynamics with macroeconomic and latent variables. Journal of Monetary Economics 50: 745-87. [CrossRef]

Angelini, Paolo. 2000. Are banks risk averse? Intraday timing of operations in the interbank market. Journal of Money Credit and Banking, 54-73. [CrossRef]

Angelini, Paolo. 2008. Liquidity and announcement effects in the euro area. Giornale degli Economisti e Annali di Economia $2008:$ 1-20.

Angelini, Paolo, Andrea Nobili, and Cristina Picillo. 2011. The interbank market after August 2007: What has changed, and why? Journal of Money Credit and Banking 43: 923-58. [CrossRef]

Baglioni, Angelo, and Andrea Monticini. 2008. The Intraday Price of Money: Evidence from the e-MID Interbank Market. Journal of Money, Credit and Banking 40: 1533-40. [CrossRef]

Baglioni, Angelo, and Andrea Monticini. 2010. The intraday interest rate under a liquidity crisis: The case of August 2007. Economics Letters 107: 198-200. [CrossRef]

Baglioni, Angelo, and Andrea Monticini. 2013. Why does the interest rate decline over the day? Evidence from the liquidity crisis. Journal of Financial Services Research 44: 175-86. [CrossRef]

Ball, Alan, Edward Denbee, Mark J. Manning, and Anne Wetherilt. 2011. Intraday Liquidity: Risk and Regulation. Bank of England Financial Stability Paper 11. London: Bank of England.

Barucca, Paolo, and Fabrizio Lillo. 2018. The organization of the interbank network and how ECB unconventional measures affected the e-MID overnight market. Computational Management Science 15: 33-53. [CrossRef]

Birz, Gene, and John R. Lott Jr. 2011. The effect of macroeconomic news on stock returns: New evidence from newspaper coverage. Journal of Banking and Finance 35: 2791-800. [CrossRef]

BIS. 2005. Zero-Coupon Yield Curves: Technical Documentation. BIS Papers No. 25. Basel: BIS.

Bomfim, Antulio N. 2003. Pre-announcement effects, news effects, and volatility: Monetary policy and the stock market. Journal of Banking and Finance 27: 133-51. [CrossRef] 
Bonner, Clemens, and Sylvester Eijffinger. 2013. The Impact of Liquidity Regulation on Interbank Money Markets. Centre for Economic Policy Research Discussion Paper 9124. London: Centre for Economic Policy Research.

Brenner, Menachem, Paolo Pasquariello, and Marti Subrahmanyam. 2009. On the volatility and comovement of US financial markets around macroeconomic news announcements. Journal of Financial and Quantitative Analysis 44: 1265-89. [CrossRef]

Brossard, Olivier, and Susanna Saroyan. 2016. Hoarding and short-squeezing in times of crisis: Evidence from the Euro overnight money market. Journal of International Financial Markets, Institutions and Money 40: 163-85. [CrossRef]

Brunetti, Celso, Mario Di Filippo, and Jeffrey H. Harris. 2010. Effects of central bank intervention on the interbank market during the subprime crisis. Review of Financial Studies 24: 2053-83. [CrossRef]

Caporale, Guglielmo Maria, John Hunter, and Faek Menla Ali. 2014. On the linkages between stock prices and exchange rates: Evidence from the banking crisis of 2007-2010. International Review of Financial Analysis 33: 87-103. [CrossRef]

Cappelletti, Giuseppe, Antonio De Socio, Giovanni Guazzarotti, and Enrico Mallucci. 2011. The Impact of the Financial Crisis on Inter-Bank Funding: Evidence from Italian Balance Sheet Data. Bank of Italy Occasional Paper No. 95. Available online: https:/ / ssrn.com/abstract=1968913 (accessed on 4 May 2021).

Cassino, Enzo, Neil Cribbens, and Tugrul Vehbi. 2014. Determinants of the New Zealand Yield Curve: Domestic vs. Foreign Influences; New Zealand Treasury Working Paper No. 14/19. Wellington: New Zealand Treasury.

De Socio, Antonio. 2013. The interbank market after the financial turmoil: Squeezing liquidity in a "lemons market" or asking liquidity "on tap". Journal of Banking and Finance 37: 1340-58. [CrossRef]

Diebold, Francis X., and Canlin Li. 2006. Forecasting the term structure of government bond yields. Journal of Econometrics 130: 337-64. [CrossRef]

Diebold, Francis X., Glenn D. Rudebusch, and S. Boragan Aruoba. 2006. The macroeconomy and the yield curve: A dynamic latent factor approach. Journal of Econometrics 131: 309-38. [CrossRef]

Diebold, Francis X., Monika Piazzesi, and Glenn D. Rudebusch. 2005. Modeling bond yields in finance and macroeconomics. American Economic Review 95: 415-20. [CrossRef]

Engle, Robert F., and Victor K. Ng. 1993. Measuring and testing the impact of news on volatility. The Journal of Finance 48: 1749-78. [CrossRef]

Estrella, Arturo, and Frederic S. Mishkin. 1999. Rethinking the role of NAIRU in monetary policy: Implications of model formulation and uncertainty. In Monetary Policy Rules. Edited by J. Taylor. Chicago: University of Chicago Press, pp. 405-36.

Estrella, Arturo, and Gikas A. Hardouvelis. 1991. The term structure as a predictor of real economic activity. The Journal of Finance 46: 555-76. [CrossRef]

European Central Bank (ECB). 2011. Euro Money Market Study. Frankfurt: European Central Bank.

Fama, Eugene. 1970. Efficient capital markets: A review of theory and empirical work. The Journal of Finance 25: 383-417. [CrossRef]

Fricke, Daniel, and Thomas Lux. 2015. Core-periphery structure in the overnight money market: Evidence from the e-mid trading platform. Computational Economics 45: 359-95. [CrossRef]

Furfine, Craig. 2001. Banks as Monitors of Other Banks: Evidence from the Overnight Federal Funds Market. The Journal of Business 74: 33-57. [CrossRef]

Furfine, Craig. 2002. The interbank market during a crisis. European Economic Review 46: 809-20. [CrossRef]

Gabbi, Giampaolo, Guido Germano, Vasilis Hatzopoulos, Giulia Iori, and Mauro Politi. 2012. Market Microstructure, Bank's Behavior and Interbank Spreads. Working Paper. London: University of London.

Ganchev, Alexander. 2009. Modeling the Yield Curve of Spot Interest Rates Under the Conditions in Bulgaria, International ed. Working Paper. Sofia: Academy of Economics, Department of Finance and Credit, Narodnostopanski Arhiv, pp. 119-37.

Green, Christopher, Ye Bai, Victor Murinde, Kethi Ngoka, Isaya Maana, and Samuel Tiriongo. 2016. Overnight interbank markets and the determination of the interbank rate: A selective survey. International Review of Financial Analysis 44: 149-61. [CrossRef]

Green, Christopher. 2011. The day the music died: The financial "tsunami" of 2007-2009. In The Financial Crisis and the Regulation of Finance. Edited by Green Christopher, Eric J. Pentecost and Thomas G. Weyman-Jones. Cheltenham: Edward Elgar, pp. 9-29.

Guidolin, Massimo, and Yu Man Tam. 2013. A yield spread perspective on the great financial crisis: Break-point test evidence. International Review of Financial Analysis 26: 18-39. [CrossRef]

Gürkaynak, Refet S., Brian Sack, and Jonathan H. Wright. 2007. The US Treasury yield curve: 1961 to the present. Journal of Monetary Economics 54: 2291-304. [CrossRef]

Hakkio, Craig S., and Douglas K. Pearce. 1985. The reaction of exchange rates to economic news. Economic Inquiry 23: 621-36. [CrossRef]

Hanousek, Jan, Evžen Kočenda, and Ali M. Kutan. 2009. The reaction of asset prices to macroeconomic announcements in new EU markets: Evidence from intraday data. Journal of Financial Stability 5: 199-219. [CrossRef]

Hatzopoulos, Vasilis, and Giulia Iori. 2012. Information Theoretic Description of the e-Mid Interbank Market: Implications for Systemic Risk. Working Paper Report No. 12/04. London: University of London.

Hatzopoulos, Vasilis, Giulia Iori, Rosario N. Mantegna, Salvatore Miccichè, and Michele Tumminello. 2015. Quantifying preferential trading in the e-MID interbank market. Quantitative Finance 15: 693-710. [CrossRef]

Hautsch, Nikolaus, and Vahidin Jeleskovic. 2008. Modelling High-Frequency Volatility and Liquidity Using Multiplicative Error Models. In Applied Quantitative Finance, 2nd ed. Edited by Wolfgang Härdle, Nikolaus Hautsch and Ludger Overbeck. Berlin: Spinger, pp. 379-97. 
Hewicker, Harald, and Heinz Cremers. 2011. Modellierung von Zinsstrukturkurven. Working Paper Series No. 165; Frankfurt: Frankfurt School of Finance and Management.

Hladíková, Hana, and Jarmila Radová. 2012. Term structure modelling by using Nelson-Siegel model. European Financial and Accounting Journal 7: 36-55. [CrossRef]

Hodges, Stewart D., and Naru Parekh. 2006. Term-structure slope risk: Convexity revisited. The Journal of Fixed Income 16: 54. [CrossRef]

Hurn, A. Stan, Terry Moody, and V. Anton Muscatelli. 1995. The Term Structure of Interest Rates in the London Interbank Market. Oxford Economic Papers. Oxford: Oxford Economic, pp. 418-36.

Ioannides, Michalis. 2003. A comparison of yield curve estimation techniques using UK data. Journal of Banking and Finance 27: 1-26. [CrossRef]

Iori, Giulia, Burcu Kapar, and Jose Olmo. 2012. The Cross-Section of Interbank Rates: A Nonparametric Empirical Investigation. Working Paper Report No. 12/03. London: University of London.

Iori, Giulia, Rosario N. Mantegna, Luca Marotta, Salvatore Micciche, James Porter, and Michele Tumminello. 2015. Networked relationships in the e-MID Interbank market: A trading model with memory. Journal of Economic Dynamics and Control 50: 98-116. [CrossRef]

Jurgilas, Marius, and Filip Žikeš. 2014. Implicit intraday interest rate in the UK unsecured overnight money market. Journal of Financial Intermediation 23: 232-54. [CrossRef]

Kladívko, Kamil. 2010. The Czech treasury yield curve from 1999 to the present. Finance an Uver Czech Journal of Economics and Finance 60: 307-35.

Kleinnijenhuis, Jan, Friederike Schultz, Dirk Oegema, and Wouter Van Atteveldt. 2013. Financial news and market panics in the age of high-frequency sentiment trading algorithms. Journalism 14: 271-91. [CrossRef]

Lane, Philip. 2012. The European sovereign debt crisis. The Journal of Economic Perspectives 26: 49-67. [CrossRef]

McQueen, Grant, and V. Vance Roley. 1993. Stock prices, news, and business conditions. Review of Financial Studies 6: 683-707. [CrossRef]

Meier, Iwan. 1999. Estimating the Term Structure of Interest Rates: The Swiss Case. Working Paper No. 06/99. Switzerland: Swiss National Bank.

Merrouche, Ouarda, and Jochen Schanz. 2010. Banks' intraday liquidity management during operational outages: Theory and evidence from the UK payment system. Journal of Banking and Finance 34: 314-23. [CrossRef]

Mojon, Benoit. 2010. The 2007-2009 financial crisis and the European central bank. Open Economies Review 21: 175-82. [CrossRef]

Moro, Beniamino. 2014. Lessons from the European economic and financial great crisis: A survey. European Journal of Political Economy 34: S9-S24. [CrossRef]

Nelson, Charles R., and Andrew F. Siegel. 1987. Parsimonious modeling of yield curves. Journal of Business 60: 473. [CrossRef]

Niu, Linlin, and Gengming Zeng. 2012. The Discrete-Time Framework of the Arbitrage-Free Nelson-Siegel Class of Term Structure Models. Working Paper. Available online: https:/ / ssrn.com/abstract=1676747 (accessed on 4 May 2021).

Pearce, Douglas K., and V. Vance Roley. 1983. The reaction of stock prices to unanticipated changes in money: A note. The Journal of Finance 38: 1323-33. [CrossRef]

Piazzesi, Monika. 2005. Bond yields and the Federal Reserve. Journal of Political Economy 113: 311-44. [CrossRef]

Plummer, C. Elizabeth, and Senyo Y. Tse. 1999. The effect of limited liability on the informativeness of earnings: Evidence from the stock and bond markets. Contemporary Accounting Research 16: 541-74. [CrossRef]

Porzio, Claudio, Francesca Battaglia, Antonio Meles, and Maria Grazia Starita. 2009. Financial Turmoil and Asymmetric Information Theory: Evidence from e-MID Platform. Working Paper. Napoli: University of Napoli Parthenope.

Raddant, Matthias. 2014. Structure in the Italian overnight loan market. Journal of International Money and Finance 41: 197-213. [CrossRef]

Rangel, José Gonzalo. 2011. Macroeconomic news, announcements, and stock market jump intensity dynamics. Journal of Banking and Finance 35: 1263-76. [CrossRef]

Reppa, Zoltán. 2008. Estimating Yield Curves from Swap, BUBOR and FRA Data. Working Paper No. 73. Budapest: Magyar Nemzeti Bank (Central Bank of Hungary).

Rigobon, Roberto, and Brian Sack. 2003. Spillovers Across US financial Markets. NBER Working Paper No. w9640. Cambridge: NBER.

Ruckriegel, Karlheinz. 2011. Das Verhalten der EZB während der Finanzmarktkrise(n). Wirtschaftsdienst 91: 107-14. [CrossRef]

Rudebusch, Glenn D., and Tao Wu. 2008. A Macro-Finance Model of the Term Structure, Monetary Policy and the Economy. The Economic Journal 118: 906-26. [CrossRef]

Svensson, Lars E. O. 1994. Estimating and Interpreting Forward Interest Rates: Sweden 1992-1994. IMF Working Paper Series No 114; Washington: IMF.

Swiss National Bank. 2008. Bericht zur Finanzstabilität. Bern: Swiss National Bank.

Vento, Gianfranco A., and Pasquale La Ganga. 2009. Bank liquidity risk management and supervision: Which lessons from recent market turmoil. Journal of Money, Investment and Banking 10: 78-125.

Wiemers, Jürgen, and Ulrike Neyer. 2003. Why Do We Have an Interbank Money Market? IWH-Diskussionspapiere, No. 182. Halle: IWH. 